\title{
FITOSSANIDADE
}

\section{REAÇÃO DE ACESSOS DE LYCOPERSICON SPP. A UM ISOLADO DE POTATO VIRUS $Y\left(\mathrm{PVY}^{\mathrm{O}}\right)$ DE TOMATEIRO $\left(^{1}\right)$}

\author{
SILVIA REGINA LUZ PALAZZO $(2,4)$; ADDOLORATA COLARICCIO $\left(\left(^{*}\right)\right.$; \\ E ARLETE MARCHI TAVARES DE MELO $\left({ }^{3}\right)$
}

\begin{abstract}
RESUMO
Amostras de tomateiro (Lycopersicon esculentum Mill) 'Alambra' coletadas nas regiões produtoras de Elias Fausto, Monte-Mor e Mogi-Guaçú (SP), com sintomas de amarelecimento foliar generalizado semelhante aqueles causados por vírus foram submetidas à identificação do agente causal, por testes biológicos de transmissão mecânica, pela determinação do círculo de hospedeiras, empregando-se plantas indicadoras e diferenciadoras pertencentes às famílias Chenopodiaceae e Solanaceae pela identificação sorológica por PTA-ELISA do Potato virus Y (PVY), Pepper yellow mosaic virus (PepYMV), Cucumber mosaic virus (CMV), Tomato mosaic virus (ToMV) e DAS-ELISA com antissoros policlonais para as espécies Tomato spot wilt virus (TSWV), Tomato chlorotic spot virus (TCSV), Groundnut ringspot virus (GRSV), Chrysanthemum stem necrosis virus (CSNV) e anticorpos monoclonais para as estirpes do PVY comum (PVYO), PVY necrótico $\left(\mathrm{PVY}^{\mathrm{N}}\right)$ e PVY clorótico $\left(\mathrm{PVY}^{\mathrm{C}}\right)$. Das amostras coletadas 19 reagiram positivamente, com o PVY em PTAELISA e PVYO em DAS-ELISA. Plantas de Chenopodium amaranticolor reagiram com sintoma local e plantas de Nicotiana glutinosa, N. tabacum 'WB', N. sylvestris, N.debneyi, N. tabacum 'Sansun' reagiram com sintomas de mosaico sistêmico; tomateiros 'Alambra' manifestaram sintomas de mosaico-amarelo. Plantas de Datura stramonium, D. metel e C. annuum 'Magda' não foram infectadas. A ausência de sintomas em C.annuum 'Magda', identificou a presença do PVY patotipo 1 (PVY 1$)$, nas 19 amostras. Como foi identificada a mesma espécie de vírus nas amostras, optou-se pela inoculação do isolado de tomate 'Alambra' de Elias Fausto nos dezenove acessos de Lycopersicon spp. do Banco Ativo de Germoplasma (BAG)- IAC. O delineamento dos experimentos foi inteiramente casualizado. A reação dos acessos foi avaliada pela manifestação dos sintomas, pelos resultados positivos ou negativos após testes de retro-inoculação e PTA-ELISA, pela análise do $\chi^{2}$ utilizando-se a proporção de plantas sintomáticas e assintomáticas, com resultados positivos ou que não manifestaram sintomas e reagiram negativamente, em PTA-ELISA, constituindo, portanto fontes potenciais de genes de resistência para o PVY em tomate.
\end{abstract}

Palavras-chave: Lycopersicon spp., Resistência genética, Potato virus $\mathrm{Y}, \mathrm{PVY}^{\mathrm{O}}-1$.

$\left({ }^{1}\right)$ Recebido para publicação em 27 de janeiro de 2005 e aceito em 5 de julho de 2007.

$\left({ }^{2}\right)$ Centro de Pesquisa e Desenvolvimento de Sanidade Vegetal, Instituto Biológico, Caixa Postal 7119, 04014-002 São Paulo (SP).

E-mail: silviapalazzo@yahoo.com.br; colariccio@biologico.sp.gov.br $\left(^{*}\right)$ Autora correspondente.

$\left({ }^{3}\right)$ Centro de Horticultura (IAC), Caixa Postal 28, 13012-970 Campinas (SP). E-mail: arlete@iac.sp.gov.br

$\left({ }^{4}\right)$ Com bolsa de Mestrado CAPES. 


\title{
ABSTRACT \\ REACTION OF ACCESSES OF LYCOPERSICON SPP. TO AN ISOLATE OF POTATO VIRUS Y $\left(\mathrm{PVY}^{\mathrm{O}}\right)$ IN TOMATO
}

\begin{abstract}
Samples of tomato (Lycopersicon esculentum Mill) 'Alambra' were collected in commercial fields of Elias Fausto, Monte-Mor and Mogi-Guaçu, SP. The plants with virus-like symptoms, especially yellow mosaic were submitted, to biological and serological identification tests. For biological tests, the host range was determined by indicator and differential plants in the family Chenopodiaceae and Solanaceae. The serological identification was made by PTA-ELISA with polyclonal antiserum against Tospovirus, Tobamovirus, Potyvirus and Cucumovirus and by DAS-ELISA, by using monoclonal antibodies against PVY common strain $\left(\mathrm{PVY}^{\mathrm{O}}\right)$, PVY chlorotic strain $\left(\mathrm{PVY}^{\mathrm{C}}\right)$ and PVY necrotic strain $\left(\mathrm{PVY}^{\mathrm{N}}\right)$. All the tested samples showed positive reaction in PTA-ELISA with antiserum against PVY and negative reaction with the antiserum against the remaining viruses. In DAS-ELISA, positive reaction occurred with PVY common strain. Among the host plants, Chenopodium amaranticolor reacted with local lesions, while N. glutinosa and N. tabacum 'WB' showed systemic mosaic and the 'Alambra' reacted with yellow mosaic, while Datura stramonium, D. metel and C. annuum 'Magda' were not infected. The reaction on the differential host $C$. annuum 'Magda' permitted to identify the PVY pathotype 1 in all the 19 samples. To evaluate the reaction of the 19 accesses of Lycopersicon spp. from the IAC active bank of germoplasm, one of the samples of tomato 'Alambra' from Elias Fausto was inoculated on tomato accesses and also, the variety 'Alambra' was used as a positive control. The experiments delineation was randomized and the plant reaction was evaluated by presence and type of symptoms, and also by positive and negative results after back inoculation and serological tests (PTA-ELISA), and by analysis of $\chi^{2}$ using the ratios between symptomatic and asymptomatic plants with positive or negative results in ELISA. It was verified that most evaluated accesses were tolerant to $\mathrm{PVY}^{\mathrm{O}}-1$, but the wild species L. peruvianum B, LA-371-2 and radiated $1 \mathrm{C}$ had a great number of asymptomatic plants with negative results by ELISA, constituting potential sources of genes of resistance against PVY in tomatoes.
\end{abstract}

Key words: Lycopersicon spp., Genetic resistance, Potato virus Y, PVYO-1.

\section{INTRODUÇÃO}

No Brasil, o cultivo do tomateiro é uma das atividades agrícolas de maior expressão econômica, ocupando uma área plantada de 60 mil hectares, responsável pela produção de 3,5 milhões de toneladas, sendo 1,7 milhões de toneladas na Região Sudeste e 893 mil toneladas na Região Centro-Oeste (IBGE, 2004).

Na Região Sudeste destacam-se como maiores produtores os Estados de São Paulo e de Minas Gerais, sendo a maior região produtora de São Paulo, os municípios de Elias Fausto, Sumaré, Mogi-Guaçu e Campinas, nos quais o tomateiro é a principal olerácea plantada de outubro a março de cada ano. Na região, o principal híbrido plantado até 2002/2003 era 'Carmen', porém devido ao fato de doenças causadas por vírus, principalmente geminivírus, terem se constituído, em fatores limitantes para a produção de tomate, alguns produtores, atualmente, também têm cultivado o híbrido Alambra na região.

Além dos geminivírus, outras viroses têm ocorrido na cultura do tomateiro nesta região. No fim de 2003 e início de 2004, foram observados em diversas lavouras surtos epidêmicos de vírus em tomateiros 'Alambra', causando sintomas de mosaicoamarelo intenso e redução dos folíolos. Na maior parte das lavouras foi observado, que em $100 \%$ das plantas ocorriam esses sintomas, que foram associados às espécies Potato virus Y (PVY) e Pepper yellow mosaic virus (PepYMV) (Palazzo et al., 2004). Outros surtos do mosaico amarelo do pimentão em tomateiro 'Alambra' também foram relatados na região serrana do Espírito Santo (Maciel-Zambolim et al., 2004; Ávila et al., 2004).

No Brasil, a ocorrência do PVY em tomateiro foi observada pela primeira vez por Costa et al. (1960), causando sintomas de risca amarela nas plantas. O PVY causou graves problemas na cultura durante a década de 60, quando foram desenvolvidas por NAGAi $(1969,1972)$ variedades de tomateiros resistentes ao PVY, possibilitando o avanço da cultura no Estado de São Paulo.

O surgimento de novo surto de PVY ocorrendo em tomateiro no Estado de São Paulo relatado por Palazzo et al. (2004) reflete a sistemática substituição de cultivares de tomateiros com resistência genética aos isolados de PVY existentes na região (ÁvILA et al., 2004).

As principais fontes de resistência ao PVY foram detectadas na espécie selvagem de tomateiro Lycopersicon hirsutum PI247087 (THOMAs, 1981; GEBRESeLASSIE et al., 1987; LegnANi et al., 1995). O PVY infecta naturalmente, as principais solanáceas cultivadas, 
como batata, pimentão, tomate e fumo. Perdas de 50$100 \%$ devido à infecção por PVY foram registradas, em tomateiro na Índia (Behl e Chowfla, 1989), Austrália (Thomas e McGrath, 1988), Canadá (StobBS et al., 1994), França (Gebre-Selassie, 1985; Marchoux et al., 1995) e Espanha (BlAnCo-URGOITI et al., 1998; Romero et al., 2001; Parella et al., 2002).

Para a identificação e classificação do PVY podem-se empregar critérios sintomatológicos com a utilização de plantas indicadoras (MATtHEUs, 1993); sorológicos com a utilização de anticorpos monoclonais contra as diferentes estirpes de PVY (Mattheus, 1991; Shukla et al., 1994) e moleculares onde as sequiências de nucleotídeos ou aminoácidos do genoma viral são utilizadas para classificar as espécies e estirpes do gênero Potyvirus (Inoue-Nagata et al., 2001).

O presente trabalho teve como objetivos: a identificação biológica e sorológica de isolados de vírus de tomateiro híbrido Alambra coletados nas principais regiões produtoras de Campinas e da avaliação da reação de acessos de Lycopersicon spp. do banco ativo de germoplasma do Instituto Agronômico (IAC) a um destes isolados, em condições de casa de vegetação, para identificar possíveis fontes de resistência ao PVY, para futura utilização em programas de melhoramento de tomate.

\section{MATERIAL E MÉTODOS}

\section{Identificação do vírus}

Foram coletadas 19 amostras de plantas de tomate híbrido Alambra, procedentes de Elias Fausto, Monte-Mor e Mogi-Guaçu (SP) entre março de 2003 e outubro de 2004, com sintomas de amarelecimento foliar generalizado e reduções foliares que foram analisadas no Laboratório de Fitovirologia e Fisiopatologia (LFF) do Instituto Biológico por meio de testes biológicos e de sorologia, a fim de identificar o vírus presente nas amostras.

Foram realizados testes sorológicos de PTAELISA (ClaRK e AdAMS, 1977) para as espécies Potato virus Y (PVY), Pepper yellow mosaic virus (PepYMV), Cucumber mosaic virus (CMV), Tomato mosaic virus (ToMV) e DAS-ELISA (CLARK e AdAMS, 1977) com antissoros policlonais para as espécies Tomato spot wilt virus (TSWV), Tomato chlorotic spot virus (TCSV), Groundnut ringspot virus (GRSV), Chrysanthemum stem necrosis virus (CSNV) e anticorpos monoclonais para as estirpes do PVY comum $\left(\mathrm{PVY}^{\mathrm{O}}\right)$, PVY necrótico $\left(\mathrm{PVY}^{\mathrm{N}}\right)$ e PVY clorótico $\left(\mathrm{PVY}^{\mathrm{C}}\right)$. Nos testes de ELISA foram utilizados controles positivos e negativos para cada um dos vírus analisados. A leitura foi realizada em ELISA reader a $405 \mathrm{~nm}$ de comprimento de onda e foram considerados positivos os valores de leitura das amostras infectadas, com leitura três vezes maior do que aquela obtida para as plantas sadias.

Para a determinação do círculo de hospedeiras foram selecionadas as seguintes espécies indicadoras: Chenopodium amaranticolor (Chenopodiaceae), Lycopersicon esculentum 'Santa Cruz', 'Carmen', 'Alambra', Nicotiana debneyi, N. sylvestris, N. glutinosa, N. megalosiphon,, N. tabacum 'Samsun' N. tabacum 'White Burley', Datura stramonium, D. metel (Solanaceae), cultivares diferenciais de pimentão (Capsicum annuum): 'Criolo de Morellos', 'Magda', 'Yolo Wonder', 'Ikeda', 'Yolo $\mathrm{Y}^{\prime}$ e 'Florida VR-2' e cultivares comerciais de tomate: 'Alambra', 'Carmen', 'Thomas', 'Diana', 'Jumbo', 'Kindyo', 'Graziella', 'Olympia', 'Rodas $\mathrm{HQ}^{\prime}$, 'Santa Cruz', 'Romana', 'Concorde' e 'Densus'. Foram inoculadas mecanicamente, dez plantas de cada espécie com os isolados de vírus de tomateiro 'Alambra'. O inóculo foi obtido pela maceração de folhas infectadas do tomateiro na presença de tampão Tris-HCl, pH 8,0 (TACM) (DERRICK, 1973), na proporção 1:5 (g/mL) (YARWOOd, 1969), carborundum (400 mesh) e carvão ativado. Foi mantida uma planta controle, de cada espécie inoculada. As plantas foram mantidas em casa de vegetação para avaliar a manifestação e o desenvolvimento dos sintomas.

Avaliação da reação dos acessos de Lycopersicon spp. ao isolado de vírus do tomateiro 'Alambra'

Para avaliar a reação a este isolado de vírus foram testados 19 acessos de Lycopersicon spp. do Banco Ativo de Germoplasma do Centro de Horticultura do Instituto Agronômico (BAG-IAC), em Campinas, e foi incluído o híbrido 'Alambra'como controle suscetível (Tabela 1).

Para a realização dos experimentos, foram empregadas dez plantas de cada um dos acessos, as quais foram submetidas à inoculação com o isolado de vírus de tomateiro 'Alambra'. As plantas foram inoculadas inicialmente, no estádio de três folhas definitivas, seguindo-se uma segunda inoculação sete dias após a primeira. A avaliação dos sintomas foi realizada aos 30 dias após a primeira inoculação. A reação das plantas foi avaliada pela presença ou ausência dos sintomas nas plantas inoculadas, de acordo com os critérios de imunidade, resistência, tolerância e suscetibilidade (MATHEws, 2002) (Tabela 2).

Para avaliar a reação, as plantas dos diferentes acessos foram submetidas a testes de retroinoculação em plantas de N. tabacum 'WB' e de PTA-ELISA. 
Tabela 1. Acessos de Lycopersicon spp. pertencentes ao Banco Ativo de Germoplasma do Instituto Agronômico, Campinas

\begin{tabular}{|c|c|}
\hline N. ${ }^{\circ}$ de ordem & Espécie \\
\hline 1 & Lycopersicon hirsutum PI 134417 \\
\hline 2 & Lycopersicon hirsutum PI 134416 \\
\hline 3 & Lycopersicon pimpinellifolium HES 5808-02 \\
\hline 4 & Lycopersicon pimpinellifolium NAV 1062 \\
\hline 5 & Lycopersicon peruvianum 29/115 \\
\hline 6 & Lycopersicon peruvianum LA-371-2 \\
\hline 7 & Lycopersicon peruvianum \\
\hline 8 & Lycopersicon peruvianum \\
\hline 9 & Lycopersicon peruvianum PI 270435 \\
\hline 10 & Lycopersicon peruvianum irradiado $1 \mathrm{C}$ \\
\hline 11 & Lycopersicon peruvianum (roxo) \\
\hline 12 & $\begin{array}{l}{\left[\mathrm{F}_{2}\left(\text { Rio Grande } \times \mathrm{F}_{3} 1-2\right) \times \mathrm{F}_{3}\right.} \\
(\text { Santa Clara } \times \text { Lycopersicon hirsutum })]\end{array}$ \\
\hline 13 & $\begin{array}{l}\mathrm{F}_{2}(\text { Santa Clara } \times \text { L. hirsutum } 1-2 \times \text { Santa } \\
\text { Clara } \times \text { L. hirsutum 1-3) }\end{array}$ \\
\hline 14 & $\begin{array}{l}\mathrm{F}_{2}(\text { Santa Clara } \times \text { L. hirsutum } 1-3 \times \text { Santa } \\
\text { Clara } \times \text { L. hirsutum 1-2) }\end{array}$ \\
\hline 15 & $\mathrm{~F}_{2}($ Santa Clara $\mathrm{x}$ L. hirsutum $)$ \\
\hline 16 & $\begin{array}{l}\text { CNPH } 944 \text { LA } 1036 \text { Lycopersicon } \\
\text { chmielewskii }\end{array}$ \\
\hline 17 & $\begin{array}{l}\text { CNPH } 672 \text { Sugar Lamp } \mathrm{F}_{1} \text { Lycopersicon } \\
\text { esculentum var. cerasiforme }\end{array}$ \\
\hline 18 & $\begin{array}{l}\text { CNPH } 673 \text { Piko } \mathrm{F}_{1} \text { Lycopersicon } \\
\text { esculentum var. cerasiforme }\end{array}$ \\
\hline 19 & $\begin{array}{l}\text { CNPH } 674 \text { Cheloy mimi } \mathrm{F}_{1} \text { Lycopersicon } \\
\text { esculentum var. cerasiforme }\end{array}$ \\
\hline 20 & Lycopersicon esculentum $\mathrm{F}_{1}$ 'Alambra' \\
\hline
\end{tabular}

Tabela 2. Critérios adotados para avaliação do comportamento dos acessos de Lycopersicon spp. nos ensaios experimentais

\begin{tabular}{lccr}
\hline Comportamento & Sintomas & $\begin{array}{c}\text { Recuperação } \\
\text { viral } \\
\text { (Inoculação) }\end{array}$ & $\begin{array}{c}\text { Replicação } \\
\text { viral } \\
\text { (PTA-ELISA) }\end{array}$ \\
\hline Imune & Ausente & Negativa & Negativa \\
Resistente & Hipersensibilidade & Negativa & Negativa \\
Tolerante & Ausente & Positiva & Positiva \\
Suscetível & Presente & Positiva & Positiva \\
\hline
\end{tabular}

O delineamento experimental foi composto por 20 tratamentos, duas repetições e 10 plantas por parcela. As parcelas foram dispostas inteiramente ao acaso na casa de vegetação. As proporções avaliadas foram: entre plantas com e sem sintomas e entre plantas com resultados positivos e negativos em PTAELISA, de cada grupo de acessos sendo analisadas estatisticamente pelo teste $\chi^{2}$ a $1 \%$ de significância. Através desta análise testou-se a hipótese de igualdade $\left(H_{0}: r=s\right)$ contra a hipótese alternativa $\left(H_{1}\right.$ : $r$ s) (GOMEs, 1984).

\section{RESULTADOS E DISCUSSÃO}

\section{Identificação do vírus}

As 19 amostras de tomate do híbrido Alambra, procedentes de Elias Fausto, Monte-Mor e MogiGuaçu, com sintomas de amarelecimento foliar generalizado e redução do folíolo (Figura 1), manifestaram reação sorológica positiva com antissoro policlonal contra a espécie PVY e nenhuma reação para as espécies PepYMV, CMV, ToMV, TSWV, TCSV, GRSV e CSNV. Nas amostras positivas para o PVY, houve reação positiva para a estirpe comum $\left(\mathrm{PVY}^{\mathrm{O}}\right)$ e negativa para as estirpes $\mathrm{PVY}^{\mathrm{C}}$ e $P V Y^{\mathrm{N}}$, quando avaliadas em DAS-ELISA com anticorpos monoclonais.

$\mathrm{Na}$ tabela 3, estão relacionados os sintomas das plantas indicadoras submetidas à inoculação com o isolado de vírus do tomateiro 'Alambra', identificado em DAS-ELISA como PVYO; verificou-se que o vírus causou lesão local em C. amaranticolor e Nicotiana benthamiana e ausência de sintomas em Datura stramonium e $D$. metel, e não pode ser recuperado destas últimas, em plantas de N. tabacum 'White Burley'.

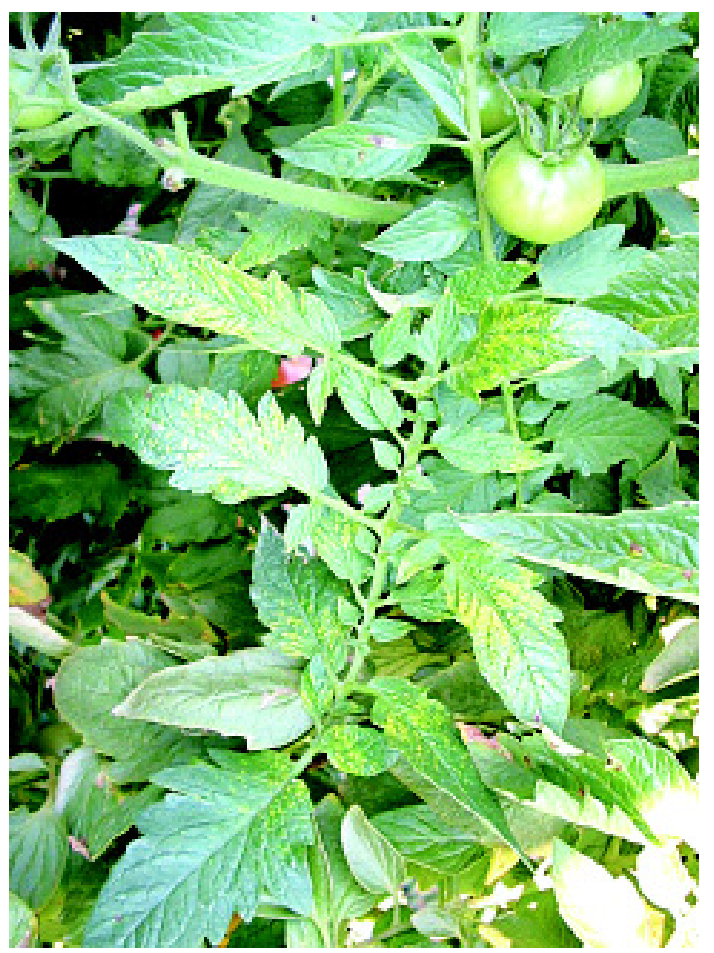

Figura 1. Tomateiro 'Alambra' coletado em Elias Fausto (SP), com sintomas de amarelecimento foliar. 
A manifestação desse isolado nas plantas indicadoras empregadas foi semelhante àquela descrita na literatura para o PVY (De BOKX e HutTinga, 1981; SHuKLA et al., 1994). O isolado em estudo não infectou o pimentão 'Magda', hospedeira natural do PepYMV, bem como D. stramonium, espécie indicadora de TEV, assim, em associação com o resultado do DAS-ELISA, o vírus em estudo foi identificado como $\mathrm{PVY}^{\mathrm{O}}$.

Tabela 3. Sintomas em espécies indicadoras, cultivares diferenciais de $C$. annuиm e cultivares comerciais de tomateiros após inoculação com o isolado de $\mathrm{PVY}$ de tomateiro 'Alambra', São Paulo março de 2004.

\begin{tabular}{|c|c|c|}
\hline Espécie/Cultivar & intoma local & Sintoma sistêmico \\
\hline C. amaranticolor & SL & AS \\
\hline Datura metel & AS & AS \\
\hline D. stramonium & AS & AS \\
\hline Nicotiana benthamiana & SL & AS \\
\hline N. tabacum 'TNN' & AS & $\mathrm{B} ; \mathrm{Mo} ; \mathrm{RF}$ \\
\hline N. tabacum 'White Burley' & $y^{\prime} \quad$ AS & $\mathrm{B} ; \mathrm{Mo} ; \mathrm{RF}$ \\
\hline N. debneyi & AS & $\mathrm{B} ; \mathrm{Mo} ; \mathrm{RF}$ \\
\hline N. glutinosa & AS & $\mathrm{B} ; \mathrm{Mo} ; \mathrm{RF}$ \\
\hline N. megalosiphom & AS & $\mathrm{B} ; \mathrm{Mo} ; \mathrm{RF}$ \\
\hline N. sylvestris & AS & $\mathrm{B} ; \mathrm{Mo} ; \mathrm{RF}$ \\
\hline N. samsum & AS & $\mathrm{B} ; \mathrm{Mo} ; \mathrm{RF}$ \\
\hline Petunia hybrida & AS & $\mathrm{B} ; \mathrm{Mo} ; \mathrm{RF}$ \\
\hline \multicolumn{3}{|l|}{ Capsicum annuum } \\
\hline 'Magda' & AS & AS \\
\hline 'Criolo de Morellos' & AS & AS \\
\hline 'Yolo Wonder' & AS & $\mathrm{B} ; \mathrm{Mo}$ \\
\hline 'Ikeda' & AS & B; Mo \\
\hline 'Yolo Y' & AS & $\mathrm{B} ; \mathrm{Mo}$ \\
\hline 'Delray Bell' & AS & AS \\
\hline 'Myr 10' & AS & AS \\
\hline 'Florida VR-2' & AS & AS \\
\hline \multicolumn{3}{|l|}{ L. esculentum } \\
\hline 'Alambra' & AS & Mo;RA;RF \\
\hline 'Carmen' & AS & Mo;RA;RF \\
\hline 'Concorde' & AS & Mo;RA;RF \\
\hline 'Densus' & AS & Mo;RA;RF \\
\hline 'Diana' & AS & Mo;RA;RF \\
\hline 'Graziela' & AS & Mo;RA;RF \\
\hline 'Jumbo' & AS & Mo;RA;RF \\
\hline 'Kindyo' & AS & Mo;RA;RF \\
\hline 'Olympia' & AS & Mo;RA;RF \\
\hline 'Rodas HQ' & AS & Mo;RA;RF \\
\hline 'Romana' & AS & Mo;RA;RF \\
\hline 'Thomas' & AS & Mo;RA;RF \\
\hline
\end{tabular}

Sintomas: $\mathrm{SL}=$ sintoma local; $\mathrm{B}=$ bolhosidade; $\mathrm{Mo}=$ mosaico; $\mathrm{RA}=$ risca amarela; $\mathrm{AS}=$ ausência de sintomas; $\mathrm{RF}=$ redução foliar; $\mathrm{RA}=$ risca amarela.
Pela reação das plantas indicadoras, $N$. glutinosa, N. tabacum 'TNN', N. sylvestris, C. amaranticolor e D. stramonium (Tabela 3), constatou-se a ausência de Tobacco mosaic virus (TMV) e ToMV nas amostras avaliadas.

A reação das cultivares de $C$. annuum contendo genes de resistência aos diferentes patotipos do PVY revelou a presença do vírus na amostra de tomate isolado 'Alambra' - PVY patotipo 1 - de acordo com a classificação de GeBRE-SELASSIE et al. (1985), uma vez que nas cultivares 'Ikeda', 'Yolo Wonder' e 'Yolo Y' ocorreram sintomas de mosaico sistêmico, enquanto em 'Florida VR-2' e 'Magda', o mesmo não foi observado (Tabela 3). Os isolados de tomateiro avaliados neste experimento foram transmitidos mecanicamente para pimentão, embora algumas das espécies avaliadas não tenham manifestado sintomas.

Todas as cultivares comerciais de tomateiro foram sintomáticas ao isolado 'Alambra' (Tabela 3), ocorrendo, nos tomateiros em casa de vegetação, a reprodutibilidade dos sintomas de amarelecimento foliar e redução dos folíolos, observados em campo para o tomateiro 'Alambra' (Figura 2). Os sintomas de mosaico, riscas amarelas e redução foliar são considerados sintomas típicos para a infecção por Potyvirus em tomateiro.

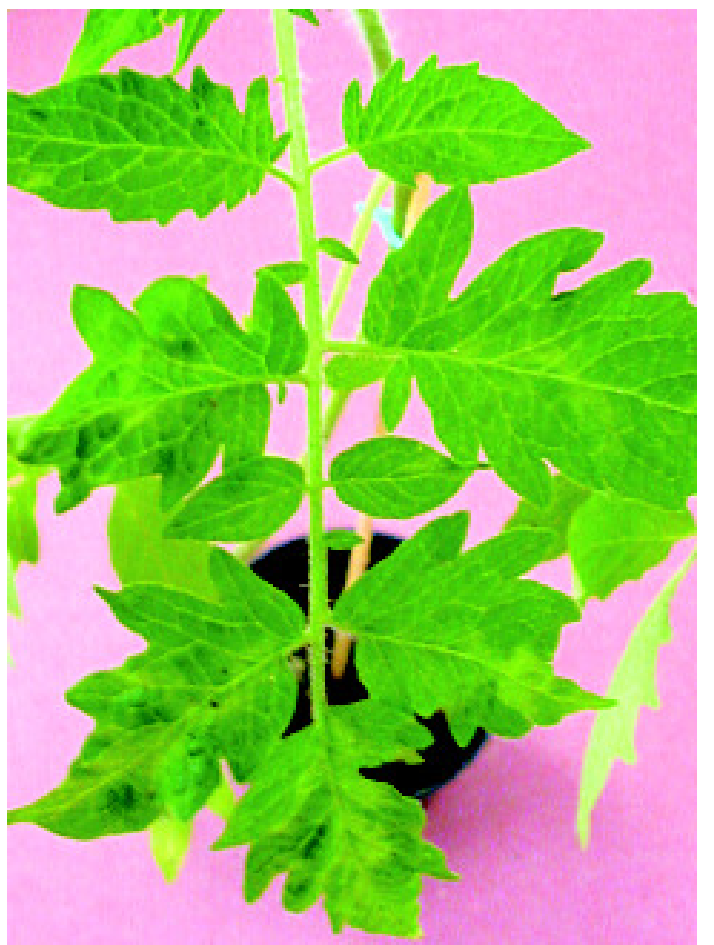

Figura 2. Tomateiro 'Alambra' inoculado mecanicamente, com sintomas de amarelecimento foliar. 
As 19 amostras de tomateiro provenientes das diversas regiões estudadas tiveram o mesmo comportamento no círculo de hospedeiras avaliado neste trabalho. Os resultados possibilitaram identificar a mesma espécie de vírus, o PVY estirpe comum patotipo $1\left(\mathrm{PVY}^{\mathrm{O}}-1\right)$, nessas amostras. Optouse, porém, pela apresentação dos resultados referentes ao isolado de vírus do tomateiro 'Alambra' proveniente de Elias Fausto empregado nos experimentos de avaliação dos diferentes acessos de tomateiros (Tabela 3).

\section{Avaliação de acessos de Lycopersicon spp. ao isolado $\mathrm{PVY}^{\mathrm{O}}-1$}

Nos dois experimentos realizados em espécies selvagens - acesso 4 (L. pimpinellifolium) e acessos 8 , 10 e 11 (L. peruvianum) - observou-se ausência total de sintomas visuais, porém o vírus pode ser recuperado das folhas apicais pela inoculação mecânica em N. tabacum 'White Burley'. A maior parte das plantas dos acessos 8, 10 e 11 (L. peruvianum) e todas do acesso 4 (L. pimpinellifolium) reagiram positivamente ao AS-PVY, em PTA-ELISA, verificandose o comportamento de tolerância ao vírus, isto é, as plantas eram assintomáticas, mas o vírus foi recuperado (Tabelas 4 e 5). NAgAi e Costa (1969) obtiveram plantas com resistência satisfatória ao PVY com o cruzamento do acesso $4 \mathrm{com}$ tomateiros do tipo Santa Cruz.

Nos acessos 6, 7, 8, 10 e 11 (L. peruvianum) verificou-se que oito, três, seis, quatro e duas plantas sem sintomas, respectivamente, reagiram negativamente ao AS-PVY, em PTA-ELISA. Observouse que, pelo critério adotado, as plantas ficaram imunes nas condições avaliadas, pois foram assintomáticas e o vírus não pôde ser recuperado. Entretanto para confirmar se essas plantas são imunes, testes complementares tornam-se necessários, para avaliar a concentração do vírus nas plantas, uma vez que esse pode estar abaixo da capacidade de ser detectado pelo teste empregado. Além da imunidade e tolerância observadas nesses experimentos, outros acessos de L. peruvianum, PI 126410, PI 128660 e PI 127829, têm sido relacionados como resistentes a PVY (NAGAi et al., 1991).

Na espécie selvagem PI 134417 (L. hirsutum) foi observada a ocorrência de quatro plantas suscetíveis e seis tolerantes no experimento I (Tabela 4), e todas tolerantes no experimento II (Tabela 5). Thomas e McGrath (1988) e Legnani et al. (1995) obtiveram somente plantas suscetíveis ao avaliar $L$. hirsutum. Essa diferença pode ser atribuída, principalmente, à utilização de isolados distintos, procedentes de diversas regiões, podendo ainda tratar-se de estirpes diferentes, pois nos trabalhos citados não havia a identificação da estirpe de PVY empregada nas inoculações, podendo ainda ser consideradas as diferenças climáticas, a idade das plantas e outros fatores que interferem na manifestação dos sintomas.

Todas as plantas da PI 134416 (L. hirsutum) no experimento II foram tolerantes ao vírus, isto é, as plantas foram assintomáticas, mas o vírus foi delas recuperado. No experimento I, seis plantas foram tolerantes e quatro foram imunes. Diversos acessos de L. hirsutum são relacionados como resistentes ao PVY. Observou-se em PI 247087 (L. hirsutum) reação imune a diversos isolados de PVY (LegnANI et al., 1995).

De modo geral, nas espécies selvagens avaliadas ocorreram reações desuniformes ao $\mathrm{PVY}^{\mathrm{O}}$ 1, como nos acessos 6 e 7 (L. peruvianum) e 16 ( $L$. chmielewskii), cujas plantas manifestaram comportamento imune e suscetível. Esse fato pode se atribuído a escapes, à possível mistura de sementes e, principalmente, à alta variabilidade genética, dentro do acesso, devido à alta taxa de fecundação cruzada.

Em todas as progênies segregantes avaliadas (acessos 12, 13, 14 e 15), observaram-se plantas imunes, tolerantes e suscetíveis ao $\mathrm{PVY}^{\mathrm{O}}-1$ (Tabelas 4 e 5). As reações de imunidade e tolerância podem ter ocorrido devido aos cruzamentos entre L. hirsutum e Santa Clara, uma vez que acessos de L. hirsutum e certas cultivares Santa Clara já haviam sido relatados como resistentes ao PVY (NAGAI et al., 1991; LEGNANI et al., 1995). Os diferentes comportamentos das plantas ao vírus observados nesses experimentos podem ser atribuídos, em parte, à alta variabilidade genética das progênies (gerações $\mathrm{F}_{2}$ e $\mathrm{F}_{3}$ ).

Todas as plantas assintomáticas dos acessos 17, 18 e 19, quando submetidas ao PTA-ELISA, reagiram positivamente, indicando a presença do vírus, portanto, manifestaram comportamento de tolerância ao vírus (Tabelas 4 e 5). O comportamento uniforme dessas plantas era esperado, uma vez que esses acessos são híbridos e possuem pouca variabilidade genética.

Os tomateiros comerciais analisados foram sintomáticos e responsivos positivamente à presença do PVY, quando submetidos ao teste de retro-inoculação e PTA-ELISA. Verificou-se que as cultivares comerciais foram suscetíveis ao isolado $\mathrm{PVY}^{\mathrm{O}}$-1. O súbito reaparecimento de PVY em tomateiro no Estado de São Paulo (Palazzo et al., 2004) reflete a substituição de cultivares tradicionais (grupo Santa Cruz) com resistência genética ao PVY, por híbridos comerciais suscetíveis, nas regiões produtoras. 
Tabela 4. Reação de acessos de Lycopersicon spp. ao isolado $\mathrm{PVY}^{\mathrm{O}}-1$ no experimento I

\begin{tabular}{|c|c|c|c|c|c|c|c|c|c|}
\hline \multirow{3}{*}{ Acessos } & \multicolumn{9}{|c|}{ Experimento I } \\
\hline & \multicolumn{9}{|c|}{ Sintomas e comportamento } \\
\hline & To & CS & AS & + & - & $\mathrm{I}$ & $\mathrm{R}$ & $\mathrm{T}$ & $\mathrm{S}$ \\
\hline 1- PI 134417 & 10 & 4 & 6 & 10 & 0 & 0 & 0 & 6 & 4 \\
\hline 2- PI 134416 & 10 & 3 & 7 & 10 & 0 & 0 & 0 & 7 & 3 \\
\hline 3- HES 5808-02 & 10 & 7 & 3 & 10 & 0 & 0 & 0 & 3 & 7 \\
\hline 4- NAV 1062 & 10 & 0 & 10 & 10 & 0 & 0 & 0 & 10 & 0 \\
\hline 5- L. peruvianum 29/115 & 10 & 1 & 9 & 10 & 0 & 0 & 0 & 9 & 1 \\
\hline 6- L. peruvianum LA-371-2 & 10 & 1 & 9 & 2 & 8 & 8 & 0 & 1 & 1 \\
\hline 7- L. peruvianum & 10 & 2 & 8 & 7 & 3 & 3 & 0 & 5 & 2 \\
\hline 8- L. peruvianum & 10 & 0 & 10 & 4 & 6 & 6 & 0 & 4 & 0 \\
\hline 9- L. peruvianum PI 270435 & 10 & 1 & 9 & 10 & 0 & 0 & 0 & 9 & 1 \\
\hline 10- L. peruvianum & 10 & 0 & 10 & 6 & 4 & 4 & 0 & 6 & 0 \\
\hline 11- L. peruvianum & 10 & 0 & 10 & 10 & 0 & 0 & 0 & 10 & 0 \\
\hline 12- $\mathrm{F}_{2}\left(\right.$ Rio Grande $\left.\times \mathrm{F}_{3} 1-2\right) \times \mathrm{F}_{3}$ (Santa Clara $\times$ L. hirsutum $)$ & 10 & 0 & 10 & 7 & 3 & 3 & 0 & 7 & 0 \\
\hline 13- $\mathrm{F}_{2}$ (Santa Clara $\times$ L. hirsutum 1-2 x Santa Clara x L. hirsutum 1-3) & 10 & 8 & 2 & 8 & 2 & 2 & 0 & 0 & 8 \\
\hline 14- $\mathrm{F}_{2}$ (Santa Clara x L. hirsutum 1-3 x Santa Clara x L. hirsutum 1-2) & 10 & 7 & 3 & 7 & 3 & 3 & 0 & 0 & 7 \\
\hline $15-\mathrm{F}_{2}($ Santa Clara $\mathrm{x}$ L. hirsutum $)$ & 10 & 8 & 2 & 8 & 2 & 2 & 0 & 0 & 8 \\
\hline 16- LA 1036 Lycopersicon chmielewskii & 10 & 3 & 7 & 10 & 0 & 0 & 0 & 7 & 3 \\
\hline 17- $\mathrm{F}_{1}$ Sugar Lamp & 10 & 0 & 10 & 10 & 0 & 0 & 0 & 10 & 0 \\
\hline 18- $\mathrm{F}_{1}$ Piko & 10 & 0 & 10 & 10 & 0 & 0 & 0 & 10 & 0 \\
\hline 19- $\mathrm{F}_{1}$ Cheloy mini & 10 & 0 & 10 & 10 & 0 & 0 & 0 & 10 & 0 \\
\hline 20- $\mathrm{F}_{1}$ 'Alambra' & 10 & 10 & 0 & 10 & 0 & 0 & 0 & 0 & 10 \\
\hline
\end{tabular}

To=total de plantas; $\mathrm{CS}=$ com sintomas; AS=ausência de sintomas; + =plantas positivas no teste de PTA-ELISA; - =plantas negativas no teste de PTA-ELISA; $\mathrm{I}=$ =imune; $\mathrm{R}=$ resistente; $\mathrm{T}=$ tolerante; $\mathrm{S}=$ suscetível.

Tabela 5. Reação de acessos de Lycopersicon spp. ao isolado PVYO-1 no experimento II

\begin{tabular}{|c|c|c|c|c|c|c|c|c|c|}
\hline \multirow{3}{*}{ Acessos } & \multicolumn{9}{|c|}{ Experimento II } \\
\hline & \multicolumn{9}{|c|}{ Sintomas e comportamento } \\
\hline & To & CS & AS & + & - & $\mathrm{I}$ & $\mathrm{R}$ & $\mathrm{T}$ & S \\
\hline 1- PI 134417 & 10 & 0 & 10 & 10 & 0 & 0 & 0 & 10 & 0 \\
\hline 2- PI 134416 & 10 & 0 & 10 & 6 & 4 & 4 & 0 & 6 & 0 \\
\hline 3- HES 5808-02 & 10 & 10 & 0 & 10 & 0 & 0 & 0 & 0 & 10 \\
\hline 4- NAV 1062 & 10 & 0 & 10 & 10 & 0 & 0 & 0 & 10 & 0 \\
\hline 5- L. peruvianum 29/115 & 10 & 4 & 6 & 10 & 0 & 0 & 0 & 6 & 4 \\
\hline 6- L. peruvianum LA-371-2 & 10 & 1 & 9 & 10 & 0 & 0 & 0 & 9 & 1 \\
\hline 7- L. peruvianum & 10 & 2 & 8 & 10 & 0 & 0 & 0 & 8 & 2 \\
\hline 8- L. peruvianum & 10 & 0 & 10 & 10 & 0 & 0 & 0 & 10 & 0 \\
\hline 9- L. peruvianum PI 270435 & 10 & 3 & 7 & 10 & 0 & 0 & 0 & 7 & 3 \\
\hline 10- L. peruvianum & 10 & 0 & 10 & 8 & 2 & 2 & 0 & 8 & 0 \\
\hline 11- L. peruvianum & 10 & 0 & 10 & 8 & 2 & 2 & 0 & 8 & 0 \\
\hline 12- $\mathrm{F}_{2}\left(\right.$ Rio Grande $\left.\times \mathrm{F}_{3} 1-2\right) \times \mathrm{F}_{3}($ Santa Clara $\times$ L. hirsutum $)$ & 10 & 0 & 10 & 10 & 0 & 0 & 0 & 10 & 0 \\
\hline 13- $\mathrm{F}_{2}$ (Santa Clara $\times$ L. hirsutum 1-2 x Santa Clara $\times$ L. hirsutum 1-3) & 10 & 7 & 3 & 7 & 3 & 3 & 0 & 0 & 7 \\
\hline 14- $\mathrm{F}_{2}$ (Santa Clara $\times$ L. hirsutum 1-3 x Santa Clara x L. hirsutum 1-2) & 10 & 8 & 2 & 9 & 1 & 1 & 0 & 1 & 8 \\
\hline $15-\mathrm{F}_{2}($ Santa Clara $x$ L. hirsutum $)$ & 10 & 8 & 2 & 9 & 1 & 1 & 0 & 1 & 8 \\
\hline 16- LA 1036 Lycopersicon chmielewskii & 10 & 0 & 10 & 8 & 2 & 2 & 0 & 8 & 0 \\
\hline 17- $\mathrm{F}_{1}$ Sugar Lamp & 10 & 0 & 10 & 10 & 0 & 0 & 0 & 10 & 0 \\
\hline 18- $\mathrm{F}_{1}$ Piko & 10 & 0 & 10 & 10 & 0 & 0 & 0 & 10 & 0 \\
\hline 19- $\mathrm{F}_{1}$ Cheloy mini & 10 & 0 & 10 & 10 & 0 & 0 & 0 & 10 & 0 \\
\hline 20- $\mathrm{F}_{1}$ 'Alambra' & 10 & 10 & 0 & 10 & 0 & 0 & 0 & 0 & 10 \\
\hline
\end{tabular}

To=total de plantas; $C S=$ com sintomas; AS=ausência de sintomas; + =plantas positivas no teste de PTA-ELISA; - = plantas negativas no teste de PTA-ELISA; $\mathrm{I}=$ imune; $\mathrm{R}=$ resistente; $\mathrm{T}=$ tolerante; $\mathrm{S}=$ suscetível. 
Tabela 6. Análise estatística pelo teste $\chi^{2}$ a $1 \%$ de significância do comportamento dos acessos de Lycopersicon spp. ao isolado $\mathrm{PVY}^{\mathrm{O}}-1$

\begin{tabular}{|c|c|c|c|c|c|c|c|c|c|}
\hline \multirow[t]{2}{*}{ Acessos } & \multicolumn{9}{|c|}{ Sintomas e comportamento } \\
\hline & To & CS & AS & $\chi^{2}$ & AS & + & - & $\chi^{2}$ & + \\
\hline & \multicolumn{3}{|c|}{$\%$} & & $\%$ & \multicolumn{2}{|c|}{$-\mathrm{n} . \mathrm{o}-$} & & $\%$ \\
\hline 1- PI 134417 & 20 & 4 & 16 & $47,0^{* *}$ & 80 & 20 & * & $81,2^{* *}$ & 100 \\
\hline 2- PI 134416 & 20 & 3 & 17 & $70,0^{* *}$ & 85 & 16 & 4 & $20,76^{* *}$ & 80 \\
\hline 3- HES 5808-02 & 20 & 17 & 3 & $74,0^{* *}$ & 15 & 20 & $*$ & $81,2^{* *}$ & 100 \\
\hline 4- NAV 1062 & 20 & 0 & 20 & $170,1^{* *}$ & 100 & 20 & $*$ & $81,2^{* *}$ & 100 \\
\hline 5- L. peruvianum 29/115 & 20 & 6 & 14 & $49,46^{* *}$ & 70 & 20 & $*$ & $81,2^{* *}$ & 100 \\
\hline 6- L. peruvianum LA-371-2 & 20 & 2 & 18 & $152,2^{* *}$ & 90 & 12 & 8 & $10,61^{* *}$ & 60 \\
\hline 7- L. peruvianum & 20 & 4 & 16 & $55,0^{* *}$ & 80 & 17 & 3 & $53,49^{* *}$ & 85 \\
\hline 8- L. peruvianum & 20 & 0 & 20 & $170,1^{* *}$ & 100 & 16 & 4 & $20,76^{* *}$ & 80 \\
\hline 9- L. peruvianum PI 270435 & 20 & 4 & 16 & $66,5^{* *}$ & 80 & 20 & 0 & $17,13^{* *}$ & 100 \\
\hline 10- L. peruvianum & 20 & 0 & 20 & $170,1^{* *}$ & 100 & 14 & 6 & $10,09 * *$ & 70 \\
\hline 11- L. peruvianum & 20 & 0 & 20 & $170,1^{* *}$ & 100 & 18 & 2 & $87,55^{* *}$ & 90 \\
\hline 12- $F_{2}$ (Rio Grande $\left.\times F_{3} 1-2\right) \times F_{3}$ (Santa Clara $\times$ L. hirsutum $)$ & 20 & 0 & 20 & $170,1^{* *}$ & 100 & 17 & 3 & $53,49 * *$ & 85 \\
\hline 13- $\mathrm{F}_{2}$ (Santa Clara $\times$ L. hirsutum 1-2 x Santa Clara x L. hirsutum 1-3) & 20 & 15 & 5 & $34,53^{* *}$ & 25 & 15 & 5 & $12,26^{* *}$ & 75 \\
\hline 14- $\mathrm{F}_{2}$ (Santa Clara $\times$ L. hirsutum 1-3 x Santa Clara $\times$ L. hirsutum 1-2) & 20 & 15 & 5 & $39,86^{* *}$ & 25 & 16 & 4 & $19,25^{* *}$ & 80 \\
\hline 15- $\mathrm{F}_{2}$ (Santa Clara $\times$ L. hirsutum $)$ & 20 & 16 & 4 & $55,0^{* *}$ & 20 & 17 & 3 & $34,98^{* *}$ & 85 \\
\hline 16- LA 1036 Lycopersicon chmielewskii & 20 & 3 & 17 & $48,95^{* *}$ & 85 & 18 & 2 & $59,11^{* *}$ & 90 \\
\hline 17- $F_{1}$ Sugar Lamp & 20 & 0 & 20 & $170,1^{* *}$ & 100 & 20 & 0 & $81,2^{* *}$ & 100 \\
\hline 18- $F_{1}$ Piko & 20 & 0 & 20 & $170,1^{* *}$ & 100 & 20 & 0 & $81,2^{* *}$ & 100 \\
\hline 19- $\mathrm{F}_{1}$ Cheloy mini & 20 & 0 & 20 & $170,1^{* *}$ & 100 & 20 & 0 & $81,2^{* *}$ & 100 \\
\hline 20- $\mathrm{F}_{1}$ 'Alambra' & 20 & 20 & 0 & $170,1^{* *}$ & 0 & 20 & 0 & $81,2^{* *}$ & 100 \\
\hline
\end{tabular}

$\mathrm{TP}=$ total de plantas; $\mathrm{CS}=$ com sintomas; $\mathrm{AS}=$ ausência de sintomas; $\% \mathrm{AS}=$ porcentagem de plantas com ausência de sintomas; + =plantas positivas no teste de PTA-ELISA; - =plantas negativas no teste de PTA-ELISA; \%+ =porcentagem de plantas positivas no teste de PTA-ELISA. ** Diferença significativa.

A análise da proporção das plantas com e sem sintomas do $\mathrm{PVY}^{\mathrm{O}}-1$ (Tabela 6) pelo teste $\chi^{2}$ mostrou diferenças significativas em todos os acessos, descartando a hipótese de igualdade entre a proporção de plantas sem e com sintomas dentro dos acessos. E o teste $\chi^{2}$ para a proporção de plantas com reação positiva e negativa no teste de PTA-ELISA indicou diferenças significativas, rejeitando a hipótese de igualdade entre as plantas positivas e negativas dentro dos acessos (Tabela 6).

Os acessos com $100 \%$ das plantas assintomáticas tiveram uma porcentagem de plantas positivas para PVY, em PTA-ELISA, que variou entre $70 \%$ e $100 \%$. Assim, mesmo quando as plantas não expressam fenotipicamente os sintomas desse vírus, a planta pode estar infectada e o vírus ser disseminado no campo pelos afídeos vetores, a partir dessas plantas assintomáticas, e atuar como fontes de infecção primária, para as novas culturas de tomate. Entre os acessos avaliados, as espécies selvagens de L. peruvianum, LA-371-2 e irradiado 1C, tiveram grande número de plantas com comportamento imune ao $\mathrm{PVY}^{\mathrm{O}}-1$, sendo as mais promissoras como fontes de resistência ao vírus. As plantas imunes das progênies segregantes foram selecionadas para dar continuidade ao programa de melhoramento do IAC.

\section{CONCLUSÕES}

1. O vírus isolado de tomateiro híbrido 'Alambra', de Elias Fausto (SP), foi identificado como PVY estirpe comum patotipo $1\left(\mathrm{PVY}^{\mathrm{O}}-1\right)$, por testes biológicos e sorológicos.

2. Os acessos de L. peruvianum LA-371-2 e o irradiado 1C constituem-se como fontes potenciais de genes de resistência ao $\mathrm{PVY}^{\mathrm{O}}-1$.

3. Nas progênies segregantes (gerações $F_{2}$ e $\mathrm{F}_{3}$ ) observaram-se plantas com comportamento imune.

\section{AGRADECIMENTOS} Mestrado.

À CAPES, pela concessão da Bolsa de

\section{REFERÊNCIAS}

ÁVILA, A.C.; INOUE-NAGATA, A.K.; COSTA, H.; BOITEUX, L.S; NEVES, L.O.Q.; PRATES, R.S.; BERTINI, L.A. Ocorrência de viroses em tomate e pimentão na região serrana do Estado do Espírito Santo. Horticultura Brasileira, Brasília, v.22, n.3, p.655-658, 2004. 
BEHL, M.K.; CHOWFLA, S.C. Resistance to necrotic strain of potato virus $\mathrm{Y}$ in tomato plants. Indian Phytopathology, New Delhi, v.42, n.4, p.555-556, 1989.

BLANCO-URGOITI, B.; SÁNCHEZ, E.; SAN ROMÁN, C.P.; DOPAZO, J.; PONZ, F. Potato virus y group $C$ isolates are a homogeneous pathotype but two different genetic strain. Journal of General Virology, Great Britain, v.79, p.2037-2042, 1998.

CLARK, M.F.; ADAMS, A.N. Characterization of the microplate method of enzyme linked immunosorbent assay for the detection of plant viruses. Journal of General Virology, Great Britain, v.34, p.475-483, 1977.

COSTA, A.S., CARVALHO, A.M.B.; KITAJIMA, E.W. Risca do tomateiro em São Paulo causada por estirpe do vírus Y. Bragantia, Campinas, v.19, p. 1111-1128, 1960.

DE BOKX, J.A.; HUTTINGA, H. Potato virus Y. In: Descriptions Plant Viruses, n $^{\circ}$ 242. Kew, England: CMI/AAB, 1981.

DERRICK, K.S. Quantitative assay for plant viruses using serologycally specific electron- microscopy. Virology, Duluth, v.56, p.652-653, 1973.

FRASER, R.S. The genetics resistance of plant viruses. Annual Review of Phytopathology, Palo Alto, v.28, p.179-200, 1990.

GEBRE-SELASSIE, K; MARCHOUX, G.; DELECOLLE, B.; POCHARD, E. Variabilité naturalles des souches du virus $Y$ de la pomme de terre dans les cultures de piment du sud-est de la France: caractérisation et classification en pathotypes. Agronomie, Paris, v.5, n.7, p.621-630, 1985.

GEBRE-SELASSIE, K.; LATERROT, H.; MARCHOUX, G. Breeding tomatoes for resistance against necrotic of potato virus Y. In: EUCARPIA MEETING IN TOMATO GENETICS AND BREEDING, Salermo, 10th, Salerno, 1987. Proceedings... Salermo: European Association for Research on Plant Breeding, 1987. v.10, p.25-29.

GOMES, F.P. A estatística moderna na pesquisa agropecuária. Piracicaba, 1984. p.91-97.

IBGE-Instituto Brasileiro de Geografia e Estatística. Levantamento Sistemático da Produção Agrícola. Rio de janeiro, 2004. p.589-601.

INOUE-NAGATA, A.K.; FONSECA, M.E.N.; LOBO, T.O.T.A.; ÁVILA, A.C.; MONTE, D.C. Analysis of the nucleotide sequence of the coat protein and $3^{\prime}$-untranslated region of two brazilian Potato virus $Y$ isolates. Fitopatologia Brasileira, Brasília, v.26, n.1, p.45-52, 2001.

LEGNANI, R.; GEBRE-SELASSIE, K.; NONO-WOMDIM, P.; GOGNALONS, P.;MORETTI, A.; LATERROT, H.; MARCHOUX, G. Evaluation and inheritance of the Lycopersicon hirsutum resistance against Potato virus Y. Euphytica, Amsterdam, v.86, n.3, p.219-226, 1995.

MACIEL-ZAMBOLIM, E.; COSTA, H.; CAPUCHO, A.S.; ÁVILA, A.C.; INOUE-NAGATA, A.K.; KITAJIMA, E.W. Surto epidemiológico do vírus do mosaico amarelo do pimentão em tomateiro na região serrana do Espírito Santo. Fitopatologia Brasileira, Brasília, v.29, n.3, p.325-327, 2004.

MARCHOUX, G.; PALLOIX, A; GEBRE-SELASSIÉ, K.; CARANTA, C; LEGNANI, R; DOGIMONT, C. Variabilité du vírus $\mathrm{Y}$ de la pomme de terre et dês potyvirus voisins. Diversité dês sources de résistance chez lê piment (Capsicum sp.). Annual du Tabac, Bergerac, v.2, p.27, 1995.

MATTHEWS, R.E.F. Plant virology. $3^{\text {rd }}$ ed. San Diego: Academic Press, 1991. p.336-342.

MATTHEWS, R.E.F. Plant virology. $4^{\text {rd }}$ ed. San Diego: Academic Press, 1993. p.443-444.

MATTHEWS, R.E.F. Plant Virology. San Diego: Academic Press, 2002. p.1001.

NAGAI, H.; COSTA, A.S. Incorporação de resistência ao mosaico Y em tomateiro. Bragantia, Campinas, v.26, p.225-232, 1969.

NAGAI, H.; COSTA, A.S. Resistência ao mosaico Y, combinada com a resistência ao mosaico comum, em tomateiro. Bragantia, Campinas, v31, p.1-8, 1972.

NAGAI, H., LOURENÇÃO, A.L.; SIQUEIRA, W.J. Tomato breeding for resistance to diseases and pests in Brazil. Acta Horticulturae, Wageningen, v.301, p.91-97, 1991.

PALAZZO, S.R.L.; BERGMANN, J.C.; CHAVES, A.I.R; EIRAS, M.; CHAGAS,C.M.; COLARICCIO, A. Surto de Potyvirus associado ao mosaico amarelo do tomateiro no Estado de São Paulo. Summa Phytopathologica, Botucatu, v.30, n.1, p.117 2004. (Resumo)

PARELLA, G.; RUFFEL, S; MORETTI, A.; MOREL, C.; PALLOIX, A.; CARANTA, C. Recessive resistance gene against potyviruses are localized in collinear genomic regions of the tomato (Lycopersicon spp.) and pepper (Capsicum spp.) genomes. Theorical and Applied Genetics, Berlin, v.105, n.6-7, p.855861, 2002.

ROMERO, A.; BLANCO-URGOITI, B.; SOTO, M.J., FERERES, A.; PONZ, F. Characterization of typical pepper isolates reveals multiple pathotypes within a single genetic strain. Virus Research, Amsterdam, v.79, p.71-80, 2001.

SHUKLA, D.D.; WARD, C.W.; BRUNT, A.A. The Potyviridae. Cambridge: University Press, 1994. 500p.

STOBBS, L.W.; POYSA, V.; SCHAGEN, J.G. van. Susceptibility of cultivars of tomato and pepper to a necrotic strain of potato virus Y. Canadian Journal of Plant Pathology, Toronto, v.16, n.1, p.43-48, 1994.

THOMAS, J.E. Resistance to potato virus Y in Lycopersicon species. Australian Plant Pathology, Rockhampton, v.10, p.67-68, 1981.

THOMAS, J. E.; McGRATH, D.J. Inheritance of resistance to potato virus $\mathrm{Y}$ in tomato. Australian Journal of Agricultural Research, Collingwood, v.39, n.3, p.475-479, 1988. (Resumo) YARWOOD, C.E. The sulphite in plant virus inoculations. Virology, Duluth, v.39, p.74-78, 1969. 